\title{
PENGEMBANGAN TES BAKAT PENCAK SILAT
}

\author{
Rony Syaifullah \\ Program Studi Pendidikan Jasmani, Kesehatan \& Rekreasi \\ Universitas Sebelas Maret \\ syaifullahrony@yahoo.com
}

\begin{abstract}
This research decribes the model of talent test of pencak silat sport of competition category which includes Anthropometic, Physiological, Biomotor and Technical. This research refers to the developmental research conveyed by Borg and Gall. From the instrument process, then it trials and applys into a small and a big sample. The result of experiment was made as the base of making Software which can be made as a model in conducting a test of talent identification especially on sport branch of Pencak Silat for age of 12-14. In the Model of this Test, there are 15 series of test consisting of Anthropometric of 4 test forms, Physiological of 3 test forms, Biomotor of 4 test forms and Tehnic 4 test forms. The results from 15 items of the test are then put in the software, a reference in the form of recommendation that the athlete candidate Has Talent of Pencak Silat, Has Enough Talent of Pencak Silat and Has Less Talent of Pencak Silat is obtained.

After obtaining the validity and the reliability of the test instrument and obtaining the norm of all test instruments and the weight of each test instrument, a software of talent test of pencak silat named "RS Silat Tallent Test". It could be concluded that the result of this research was the arrangement of a model of tallent test especially for the sport branch of Pencak Silat for the athletes of the age of 12 up to 14 had been conducted named "RS Silat Tallent Test".
\end{abstract}

Keywords : The Development, Model Test, Tallent Test of Pencak Silat

\section{PENDAHULUAN}

Banyaknya permasalahan di dunia olahraga ini semua menuntut setiap pemangku kebijakan, lembaga dan organisasi olahraga harus memperbaiki sistem dan kualitas pembinaan agar nantinya dapat memberikan sumbangan yang lebih baik bagi dunia olahraga di Indonesia. Permasalahan yang sangat mendasar adalah rekruitmen para atlet di Indonesia hanya berdasarkan hasil dari kompetisi.

Kegagalan cabang olahraga pencak silat khususnya kategori tanding sudah dirasakan sejak Sea Games di Vietnam tahun 2003. Sedangkan pada kejuaraan dunia prestasi pencak silat Indonesia mulai merosot sejak tahun 2002. Pencak silat Indonesia masih berjaya di nomor Tunggal, Ganda dan Regu sampai sekarang, sedangkan di nomor Tanding mengalami penurunan prestasi.

Rumusan masalah penelitian yang dapat diangkat adalah sebagai berikut: 
1. Bagaimanakah penyusunan instrumen tes bakat yang efektif untuk mengidentifikasi bibit atlet berbakat cabang olahraga pencak silat?

2. Bagaimanakah pengembangan perangkat lunak (software) untuk mengidentifikasi bibit atlet berbakat cabang olahraga pencak silat?

\section{KAJIAN KONSEP}

\section{Model Pengembangan}

Menurut borg and gall (1989:782) Model penelitian dan pengembangan adalah" $a$ process used develop and validate educational product". Kadang-kadang penelitian ini desebut "research based development" yang muncul sebagai strategi dan bertujuan untuk meningkatkan kualitas pendidikan. Selain untuk mengembangkan dan memvalidasi hasil-hasil pendidikan, research and development juga bertujuan untuk menemukan pengetahuanpengetahuan baru melalui basic research, atau menjawab pertanyaan-pertanyaan khusus tentang masalah-masalah yang bersifat praktis melalui, applied research yang digunakan untuk meningkatkan praktik-praktik pendidikan.

\section{Konsep Model Yang Dikembangkan}

\section{a. Bakat}

Bompa mengemukakan bahwa ada 2 metode untuk seleksi bakat, yaitu: (1) seleksi alam; dan (2) seleksi ilmiah.Bakat olahraga pencak silat merupakan suatu kemampuan khusus yang tampak dari beberapa komponen tertentu yang harus dimiliki atlet pencak silat agar berprestasi secara maksimal. Atlet berbakat pencak silat adalah mereka yang memiliki ciri-ciri khusus untuk dapat berkembang menunjang keberhasilan berprestasi di cabang olahraga pencak silat.

\section{b. Identifikasi Bakat}

Identifikasi bakat (talent identification) olahraga adalah suatu upaya yang dilakukan secara sistematik untuk mengidentifikasi seseorang yang berpotensi dalam olahraga, sehingga diperkirakan orang tersebut akan berhasil latihan dan dapat meraih prestasi puncak.

\section{c. Profil Olahraga Pencak Silat}

Cabang olahraga pencak silat dengan peraturan pertandingannya 2 menit bersih kali 3 babak dengan jeda istirahat 1 menit tiap babak maka dapat dianalisis tentang kebutuhan fisiknya. Dari pengamatan dan observasi langsung di lapangan yang penulis lakukan selama menjadi atlet pencak silat, diperoleh data sebagai berikut :

1. Setiap babak selama 2 menit bersih rata-rata pesilat melakukan gebrak 4 sampai 6 kali.

2. Setiap gebrakan yang didalamnya ada langkah dan pertarungan maksimal 6 rangkaian gerak rata-rata waktu 18 sampai dengan 22 detik.

3. Jeda waktu per gebrakan 5 sampai dengan 10 detik (recovery).

4. Istirahat per babak 1 menit (recovery)

Hasil analisis observasi yang dilakukan peneliti menunjukkan bahwa sistem energi 
pencak silat kategori tanding adalah ATP-PC $=90-95 \%$; LA $=5-10 \%$; dan $\mathrm{O}_{2}=0 \%$, dengan demikian pengembangan sistem energi mengarah pada anaerobik. Sejalan dengan hasil tersebut seorang pesilat dituntut untuk mengembangkan komponen fisik, antara lain: kapasitas anaerobik, power, dayatahan otot, kekuatan otot, kelincahan, kecepatan, kecepatan reaksi, fleksibilitas dan koordinasi.

\section{d. Kondisi Fisik Umum Pencak Silat}

Beberapa komponen fisik yang harus dikembangkan mencapai prestasi secara optimal diantaranya adalah :(1) Daya tahan (endurance), (2) Kecepatan (speed), (3) Kelincahan (agility), (4) kekuatan (strength), (5) Mobilisasi dan keluwesan gerak (Mobility olahraga Flexibility) dan kelenturan (suppleness), (6) Ketrampilan (skill) dan teknik (technique), dan (7) Lain-lain komponen yang diperlukan. Menurut Joko Pekik Fisik merupakan fondasi dari bangunan prestasi, hal ini dikarenakan faktor teknik, taktik dan psikis dapat dikembangkan dengan baik apabila atlet memiliki bekal kualitas fisik yang baik. Di dalam materi pelatihan kondisi fisik dasar disebutkan bahwa kemampuan biomotor dasar meliputi lima jenis, yaitu: kekuatan, daya tahan, kecepatan, fleksibilitas, dan koordinasi

\section{e. Kondisi Fisik Khusus Pencak Silat}

Menurut Johansyah (2016) mengatakan bahwa kemampuan fisik khusus pencak silat meliputi penampilan keterampilan pencak silat, kecepatan tendangan pencak silat, kelincahan tendangan pencak silat, koordinasi tendangan pencak silat dan power tendangan pencak silat.

\section{f. Tehnik Pencak Silat}

Pencak silat adalah seni beladiri yang kaya akan tehnik-tehnik beladiri, diantaranya adalah Tehnik pukulan, tendangan, tangkisan, belaan, elakan, sapuan, guntingan, bantingan, hindaran, egosan dan kuncian. Keayaan tehnik yang ada di pencak silat merupakan rangkuman dari seluruh beladiri yang ada di dunia ini.

\section{g. Prestasi Pencak Silat}

Prestasi pencak silat adalah suatu hasil latihan yang meliputi aspek kemampuan gerak atau fisik, keterampilan atau teknik, strategi/taktik, mental/psikologis dan aspek tak terukur yang bertujuan untuk mencapai kinerja setinggi-tingginya dalam pertandingan pencak silat. Pencapaian prestasi yang setinggi-tingginya merupakan puncak dari segala proses pembinaan, termasuk dari proses pemassalan maupun pembibitan.

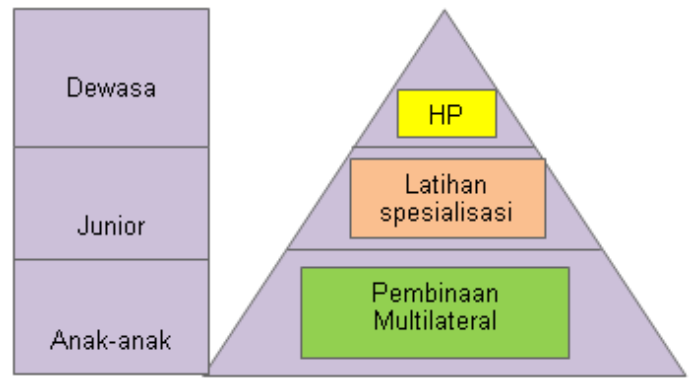

Gambar 1. Sistem Pembinaan Prestasi Olahraga Jangka Panjang

(Sumber: Tudor O. Bompa, G. Gregory Haff, 2009, hal. 3) 


\section{h. Tes Pengukuran}

Kirkendall, dkk. (1987) mengemukakan bahwa tujuan tes antara lain untuk (1) menentukan status partisipan, kemajuan yang dibuatnya, atau tingkat kemampuan yang dimiliki sehingga partisipan tersebut dapat dikelompokkan sesuai dengan kemampuannya, (2) memotivasi partisipan agar bisa berlatih lebih giat lagi, baik di dalam maupun di luar jadwal latihannya, (3) mengevaluasi efektivitas program, metode dan isi.

\section{Pengembangan Model}

\section{a. Tahap Teoritik}

Tujuan pemanduan dan pengembangan bakat olahraga menekankan pada identifikasi keberbakatan olahraga, dengan mengacu pada kesesuaian potensi dan minat atlet, identifikasi bakat olahraga bertujuan untuk memprediksi dengan probabilitas yang tinggi, tentang seberapa besar peluang seseorang untuk berhasil mencapai prestasi maksimal.

\section{b. Validitas}

Validitas adalah tingkat ketepatan penggunaan alat dengan apa yang seharusnya diukur. Validitas suatu intrumen adalah derajat yang menunjukkan di mana suatu tes mengukur apa yang hendak diukur. Suatu tes atau instrumen pengukuran adalah valid apabila ia mengukur apa yang seharusnya diukur.

\section{c. Reliabilitas}

Reliabilitas dapat diartikan sama dengan konsistensi, suatu instrumen dikatakan reliabel apabila tes yang dibuat mempunyai konsistensi yang tinggi dalam mengukur yang hendak diukur. Derajat reliabilitas dinyatakan oleh koefisien korelasi dengan rentangan dari 0,00 sampai 1,00, semakin besar skor berarti semakin reliabel.

\section{d. Obyektivitas}

Obyektivitas dapat didefinisikan sebagai persetujuan dari dua atau lebih penilai yang kompeten tentang skor suatu pengukuran. Obyektivitas dapat juga diistilahkan sebagai reliabilitas antar penilai (rater reliability).

\section{e. Administrabilitas}

Administrabilitas berkaitan dengan pertimbangan praktis dalam memilih instrumen tes. Aspek ini adalah merupakan aspek penting dari kriteria tes yang baik selama itu tidak berpengaruh negatif pada kriteria lain.

\section{f. Penskoran Hasil Tes}

Dalam melaksanakan pensekoran harus memperhatikan karakteristik yang harus dinilai, konstruksi peringkat instrumen itu sendiri, dan untuk kondisi di mana peringkat harus diperoleh. Ada dua cara yang biasa dilakukan dalam memutuskan skor atau grade 
hasil penskoran, yaitu: (1) prosedur acuan patokan (criterion referenced procedure); dan (b) prosedur acuan normative (norm referenced procedure).

\section{PENELITIAN YANG RELEVAN}

Penelitian yang relevan dengan penelitian ini diantaranya adalah sebagai berikut :

1. Penelitian Isabel Tallir, dkk. (2007) pengembangan dan validasi dari dua instrumen baru berbasis video coding untuk penilaian kinerja permainan individu anak usia 11-12 tahun pada permainan bola tangan dan sepak bola. Kesimpulan penelitian adalah instrumen yang dikembangkan memberikan metode yang valid dan dapat diandalkan untuk penilaian otentik dari pengambilan keputusan individu selama bermain.

2. Hasil penelitian A. M. Williams (2000) bahwa pemain sepak bola yang terampil dapat mengingat dan mengenali pola bermain lebih efektif daripada rekan-rekan mereka kurang terampil. Pemain terampil menggunakan pengetahuan unggul mereka untuk mengontrol pola gerakan mata yang diperlukan untuk mencari dan mengambil sumber-sumber informasi penting di lingkungannya. Pemain sepak bola terampil menggunakan strategi pencarian yang berbeda saat melihat seluruh bidang (yaitu 11 vs 11 situasi) dibandingkan dengan kelompok kecil (yaitu situasi 1 vs 1 atau 3 vs 3). Perilaku pencarian visual juga berbeda antara bermain defensif dan ofensif. Observasi ini memiliki implikasi untuk pengembangan program pelatihan persepsi dan identifikasi potensi pemain sepakbola.

\section{METODOLOGI PENELITIAN}

Penelitian ini terfokus pada pengembangan suatu model tes bakat, sehingga pendekatan dan metode yang digunakan dalam penelitian ini adalah metode penelitian dan pengembangan (research and development/R\&D), dengan desain pengembangan yang dipilih adalah merujuk pada pengembangan yang dikemukakan oleh Borg and Gall, yang terdiri dari seperti berikut

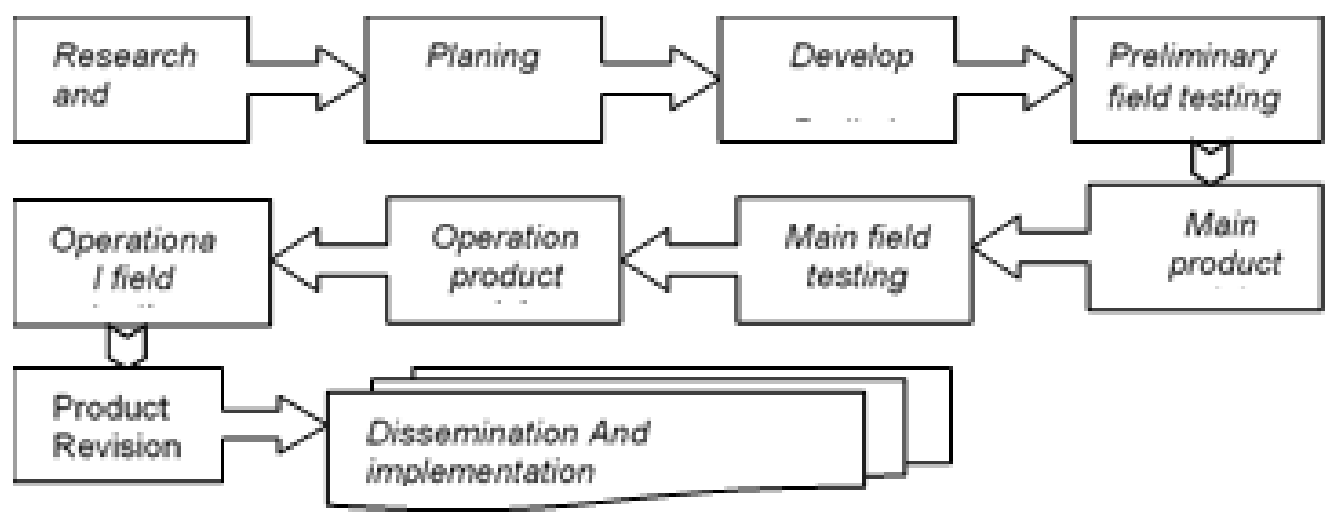

Gambar 2 . Tahap Pengembangan Model Borg and Gall (Borg, W.R. \& Gall, M.D., 1989: 783) 
Berikut langkah-langkah penelitian yang telah dilakukan yang mengacu pada penelitian pengembangan Borg dan Gall.

\section{Research and information collecting.}

Melakukan penelitian pendahuluan (prasurvei) untuk mengumpulkan informasi melalui kajian pustaka, pengamatan lapangan dan mengidentifikasi permasalahan yang dijumpai dalam pemanduan bakat olahraga pencak silat dan merangkum permasalahan

\section{Planning.}

Melakukan perencanaan (identifikasi dan definisi keterampilan, perumusan tujuan, penentuan urutan tes, dan uji ahli atau uji coba pada skala kecil atau expert judgement.

\section{Development of the preliminary from of product.}

Mengembangkan jenis/bentuk produk awal meliputi: penyiapan materi tes, penyusunan buku panduan dan perangkat evaluasi.

\section{Preliminary field testing.}

Melakukan uji coba lapangan tahap awal, dilakukan di 4 daerah dengan 126 subyek. Pengumpulan data dengan menggunakan observasi, tes dan dilanjutkan analisis data.

\section{Main product test.}

Melakukan revisi terhadap produk utama, berdasarkan masukan dan saran-saran dari para ahli dan hasil uji lapangan awal.

\section{Main field test.}

Melakukan uji coba lapangan utama, dilakukan terhadap 8 daerah, dengan 246 subyek.

\section{Operational product revision.}

Melakukan revisi terhadap produk operasional, berdasarkan masukan dan saran-saran dari para ahli dan hasil uji lapangan utama.

\section{Operational field test}

Melakukan penyusunan langkah operasional dari seluruh item tes yang merupakan produk penelitian.

\section{Final product revision.}

Melakukan revisi terhadap produk akhir, berdasarkan saran para ahli dan evaluasi dalam uji coba lapangan.

Penelitian ini hanya dilakukan sampai pada tahap ke Sembilan, sedangkan tahap yang terakhir Dissemination and implementation akan dilaksanakan pada lain waktu.

\section{HASIL DAN PEMBAHASAN}

Penyusunan produk dilaksanakan dengan mempertimbangkan hasil diskusi dan masukan dalam diskusi untuk menyusun sebuah model pemanduan bakat olahraga pencak silat dalam pembinaan cabang olahraga pencak silat. Sesuai dengan modifikasi langkah Borg dan Gall disusunlah produk awal untuk uji-coba.

1. Tinggi badan adalah jarak vertikal seseorang dari lantai ke ujung kepala (vertex), pada saat berdiri tegak. 
2. Berat badan adalah berat seseorang yang di ukur dengan menggunakan timbangan $(\mathrm{kg})$.

3. Rentang kedua lengan sama dengan lebar biacromial, yaitu jarak horisontal antara dua ujung jari tengah pada posisi lengan terentang secara menyamping setinggi bahu. Rentang lengan meliputi lebar kedua bahu dan panjang anggota badan bagian atas (tangan).

4. Panjang Tungkai, tes ini untuk mengukur panjang tungkai

5. Push-Up, adalah bentuk tes untuk mengetahui kekuatan otot bisep dan trisep. Posisi awal tidur tengkurap dengan tangan di sisi kanan kiri badan. Kemudian badan didorong ke atas dengan kekuatan tangan. Posisi kaki dan badan tetap lurus atau tegap. Setelah itu, badan diturunkan dengan tetap menjaga kondisi badan dan kaki tetap lurus. Badan turun tanpa menyentuh lantai atau tanah.

6. Sit-Up, adalah bentuk tes untuk mengetahui kekuatan bagian fleksor pinggul dan otot perut. Tes ini dimulai dengan berbaring dengan punggung di lantai, dengan kedua tangan menyentuh kedua telinga dan lutut ditekuk dalam upaya untuk mengurangi stres pada otot punggung dan tulang belakang, dan kemudian mengangkat kedua vertebra atas dan bawah dari lantai sampai kedua siku menyentuh paha.

7. Koordinasi Mata Tangan Kaki, adalah untuk mengukur koordinasi antara mata, tangan dan kaki

8. Sit and Reach, adalah untuk mengukur fleksibilitas batang tubuh dan sendi panggul

9. Lari $20 \mathrm{~m}$, tes ini bertujuan untuk mengetahui kemampuan kecepatan berlari maksimal dengan jarak $20 \mathrm{~m}$.

10. Three hop (3 hop), tes ini bertujuan untuk mengetahui kemampuan power otot tungkai dengan melakukan tiga kali lompatan horisontal berturut-turut.

11. VO2Max, dengan menggunakan Multistage Fitness Test adalah salah satu dari uji lapangan yang dirancang untuk mengukur kebugaran aerobik. Tes ini memiliki formula untuk memprediksi VO2max dari jarak lari.

12. Pukulan selama 30 detik, untuk mengukur kemampuan teknik kusus pukulan pencak silat.

13. Tendangan depan 30 detik, untuk mengukur kemampuan teknik kusus tendangan depan pencak silat.

14. Tendangan sabit 30 detik, untuk mengukur kemampuan teknik kusus tendangan sabit atau busur pencak silat.

15. Tendangan samping 30 detik, untuk mengukur kemampuan teknik khusus tendangan samping atau " $T$ " pencak silat.

\section{Hasil Uji Coba Terbatas}

Hasil uji-coba terbatas adalah didapatkannya validitas dan reliabilitas data dari instrumen tes yang disusun. Hasilnya adalah berdasarkan perhitungan statistik maka seluruh instrument tes valid dan memiliki reliabilitas yang tinggi.

Untuk uji validitas item tes, berdasarkan dari perolehan skor dari 126 sampel tersebut maka didapatlah hasil perhitungan seperti ditunjukkan pada tabel 1. 
Sedangkan untuk uji reliabilitas menggunakan rumus Alpha-Chronbach dan hasilnya Berdasarkan klasifikasi Guiford, instrumen tes pemanduan bakat olahraga pencak silat berkategori SEDANG.

\begin{tabular}{|l|l|c|c|c|c|c|}
\hline No & \multicolumn{1}{|c|}{ Item Tes } & $\begin{array}{c}\text { r xy } \\
\text { Hitung }\end{array}$ & $\begin{array}{c}\mathbf{r} \\
\text { Tabel }\end{array}$ & t Hitung & $\begin{array}{c}\mathbf{t} \\
\text { Tabel }\end{array}$ & Kriteria \\
\hline 1 & Tinggi Badan & 0,32 & 0,17 & 3,70 & 1,98 & Valid \\
\hline 2 & Berat Badan & 0,32 & 0,17 & 3,78 & 1,98 & Valid \\
\hline 3 & Rentang Kedua Lengan & 0,58 & 0,17 & 7,88 & 1,98 & Valid \\
\hline 4 & Panjang Tungkai & 0,36 & 0,17 & 3,34 & 1,98 & Valid \\
\hline 5 & Push-Up & 0,18 & 0,17 & 2,00 & 1,98 & Valid \\
\hline 6 & Sit-Up & 0,66 & 0,17 & 9,75 & 1,98 & Valid \\
\hline 7 & Koordinasi & 0,68 & 0,17 & 10,25 & 1,98 & Valid \\
\hline 8 & Sit \& Reach & 0,53 & 0,17 & 7,02 & 1,98 & Valid \\
\hline 9 & 3 Hop & 0,54 & 0,17 & 7,06 & 1,98 & Valid \\
\hline 10 & Lari 20 m & 0,61 & 0,17 & 8,61 & 1,98 & Valid \\
\hline 11 & VO2Max & 0,56 & 0,17 & 7,61 & 1,98 & Valid \\
\hline 12 & Pukulan & 0,25 & 0,17 & 2,92 & 1,98 & Valid \\
\hline 13 & Tendangan Depan & 0,18 & 0,17 & 2,05 & 1,98 & Valid \\
\hline 14 & Tendangan Sabit & 0,22 & 0,17 & 2,54 & 1,98 & Valid \\
\hline 15 & Tendangan Samping & & 0,17 & 3,35 & 1,98 & Valid \\
\hline
\end{tabular}

\section{Hasil Uji coba luas}

Pada uji luas diambil teknik sampel judgement atau purposive sampling pada 8 daerah, artinya melakukan pembagian populasi ke dalam kelompok di 8 daerah dan selanjutnya dipilih melalui sampel bertujuan (siswa umum yang berusia $12-14$ tahun yang aktif dalam pendidikan jasmani dan pembinaan pencak silat diperguruan). Total sampel pada uji coba skala luas adalah berjumlah 246 atlet (putra 126 orang dan putri 120 orang).

Berdasarkan hasil dari diskusi dengan para ahli maka, dihasilkan beberapa rujukan untuk hasil pada uji coba skala luas sebagai berikut;

1. Pembobotan pada setiap item tes. Pembobotan tersebut berdasarakan pertimbangan daya sumbang tiap item tes berbeda berdasarkan diskusi para ahli. Adapun pembobotan item tes tersebut adalah sebagai berikut : tinggi badan 3\%, berat badan 3\%, rentang kedua lengan $3 \%$, panjang tungkai $3 \%$, push-up 6\%, sit-up 6\%, koordinasi mata tangan kaki $6 \%$, flexibility $6 \%$, three hop $6 \%$, lari $20 \mathrm{~m} 8 \%$ dan multistage fitness test $10 \%$, pukulan 30 detik 10\%, tendang depan 30 detik 10\%, tendang sabit/busur 30 detik $10 \%$ dan tendang samping 30 detik $10 \%$.

2. Penentuan tiga skala norma, berbakat (B), cukup berbakat (CB) dan kurang berbakat $(\mathrm{KB})$.

3. Dalam penjumlahan item tes terlebih dahulu dilakukan penyamaan satuan menjadi skor 3, 2, dan 1. Untuk skor positif berlaku jika hasil tes besar konversi pada skor besar juga, sedangkan untuk skor negatif berlaku sebaliknya yaitu jika hasil tes besar konversi pada skor kecil.

4. Setelah menyamakan skor, kemudian dilakukan pembobotan sesuai pada item no 1 . 
Selanjutnya hasil dari kelima belas item tes tersebut dijumlahkan untuk mendapatkan skor akhir.

\section{Pedoman skor instrument}

Dari hasil uji coba luas didapatlah skor hasil tes dan pengukuran masing-masing instrumen (data mentah) yang ditranformasikan terlebih dahulu ke dalam skala 3, 2 dan 1, yaitu dengan cara memasukkan data mentah masing-masing elemen tes ke dalam norma tiaptiap item sebagai berikut:

Tabel 1. Norma Tes Bakat Pencak Silat Kelompok Putra dan Putri

\begin{tabular}{|c|c|l|}
\hline Skor & $\begin{array}{c}\text { Kategori } \\
\text { Skor }\end{array}$ & \multicolumn{1}{|c|}{ Kategori } \\
\hline$\geq 3,6$ & 3 & \multicolumn{2}{|c|}{ Berbakat Pencak Silat } \\
\hline $\begin{array}{c}1,6- \\
3,5\end{array}$ & 2 & $\begin{array}{l}\text { Cukup } \\
\text { Silat }\end{array}$ \\
\hline$\leq 1,5$ & 1 & $\begin{array}{l}\text { Kurang } \\
\text { Silat }\end{array}$ \\
\hline
\end{tabular}

Setelah melalui proses uji coba terbatas, merevisi produk dan dilaksanakan uji coba luas maka berdasarkan hasil analisis dan diskusi di hasilkan format model tes pemanduan bakat olahraga pencak silat dengan nama "RS Talent Test". Yaitu aplikasi tes bakat olahraga pencak silat dalam bentuk software.

\section{KESIMPULAN}

1. Model tes pemanduan bakat olahraga pencak silat dengan nama "RS Silat Talent Test". adalah sebagai suatu proses, rangkaian atau runtutan perubahan, di dalam memunculkan atau mengidentifikasi bakat olahraga tertentu sebagai langkah operasional dari penerapan strategi tertentu dalam memandu bakat olahraga pencak silat. Tujuan tes pemanduan bakat olahraga pencak silat menekankan pada identifikasi keberbakatan olahraga pencak silat dengan mengacu pada kesesuaian potensi dan minat peseta tes serta bertujuan untuk memprediksi dengan probabilitas yang tinggi tentang seberapa besar peluang seseorang untuk berhasil

2. Setelah melalui proses pengembangan model melalui tahap yang merupakan modifikasi dari model Borg dan Gall maka penelitian ini menghasilkan sebuah Model Pemanduan Bakat Olahraga Pencak Silat yang siap digunakan dalam memunculkan atau mengidentifikasi bakat olahraga pencak silat sebagai langkah operasional dari penerapan strategi tertentu dalam memandu bakat olahraga pencak silat.

3. Model Pemanduan Bakat Olahraga Pencak silat berisi lima belas unit item tes. Lima belas item tes yang sebelumnya dilakukan konversi ke dalam norma skor 1, 2 dan 3 yang sudah dilakukan pembobotan yang disesuaikan dengan tingkat kebutuhan dalam olahraga pencak silat. Pembobotan tiap item tes tersebut adalah; tinggi badan 3\%, berat badan 3\%, rentang kedua lengan 3\%, panjang tungkai 3\%, three hop 6\%, lari $20 \mathrm{~m} \mathrm{8 \%}$, multistage fitness test $8 \%$, push-up $6 \%$, sit-up $6 \%$, koordinasi mata tangan kaki $6 \%$, flexibility $6 \%$, 
pukulan 30 detik 10\%, tendang depan 30 detik 10\%, tendang sabit/busur 30 detik $10 \%$ dan tendang samping 30 detik $10 \%$.

4. Hasil pengujian lapangan dan hasil diskusi/validasi dengan pakar ditemukan bahwa Model Pemanduan Bakat Olahraga Pencak Silat dapat berimplikasi pada terlahirnya norma keberbakatan olahraga pencak silat tersebut, maka akan diketahui apakah seseorang memiliki potensi dalam cabang olahraga pencak silat sesuai klasifikasi atau tidak.

\section{Produk Software Tes Bakat Pencak Silat:}

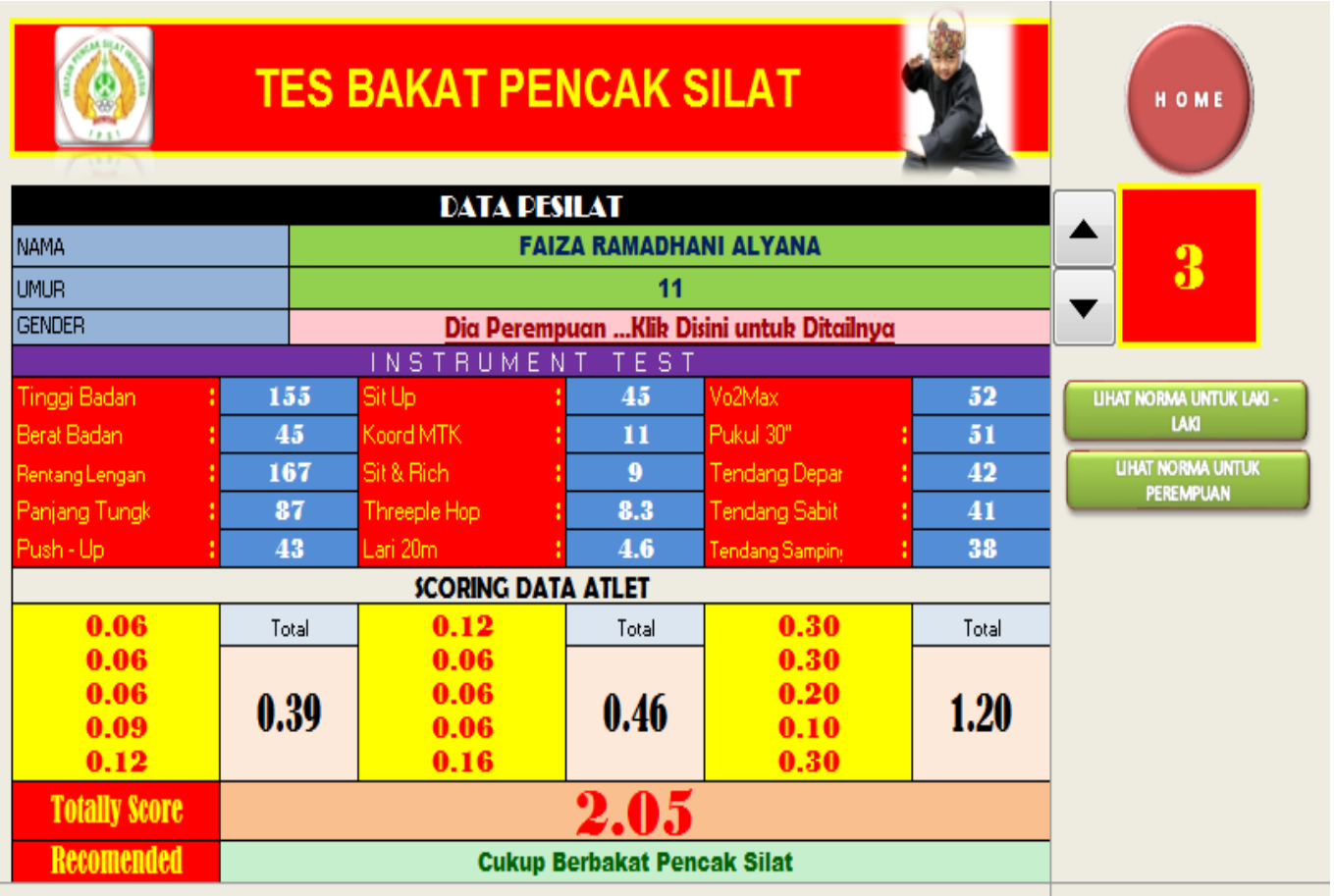

\section{DAFTAR PUSTAKA}

Benny A.Pribadi. Model desain Sistem Penelitian. Jakarta: Dian Rakyat. 2009.

Borg,W.R.\&Gall,M.D.Gall, Educational research: An Introduction, Fifth Editional. New York: Longma. 1989.

Djoko Pekik Irianto, dkk., Materi Pelatihan Kondisi Fisik Dasar, Jakarta: Asdep Pengembangan Tenaga dan Pembina Keolahragaan, Kemenpora, 2009.

Doug MacCurdy, Talent Identification Around The World, www.itftennis.com, (diakses 2 januari 2013)

Isabel Tallir, Eliane Musch, Kristof Lannoo dan Joeri Van de Voorde Validation of video-based instruments for the assessment of game performance in handball and soccer. Belgia: Ghent University, 2007. 
James Tangkudung, Kepelatihan Olahraga "Pembinaan Prestasi Olahraga" .Jakarta : Cerdas jaya. 2006.

Johansyah Lubis \& Hendro Wardoyo. Pencak Silat. Jakarta: Rajawali Sport. 2016.

Djoko Pekik Irianto, dkk., Materi Pelatihan Kondisi Fisik DasarJakarta: Asdep Pengembangan Tenaga dan Pembina Keolahragaan, Kemenpora, 2009

Kent L. Gustafson dan Robert Maribe Branch, Survey of Instructional Development Models. New York: ERIC Clearinghouse on Information \& Technology. 2002.

Kirkendall, dkk., Measurement and Evaluation for Physical Educators. Champaign: Human Kinetics Publishers. 1980.

Reilly T, Williams AM, Nevill A, Franks A., A multidisciplinary approach to talent identification in soccer. Liverpool: John Moores University Research Institute for Sport and Exercise Sciences, Journal Sports Sci. 18, Sep, 2000.

Tudor O. Bompa, Periodization: Theory and Methodology of Training $4^{\text {th }}$ edition New York: Kendal/Hunt Publishing Company, 2009

Utami Munandar, et al. Anak-anak Berbakat Pembinaan dan Pendidikannya. Jakarta: CV Rajawali,1982.

Williams AM, Perceptual skill in soccer: Implications for talent identification and development. Liverpool: John Moores University Research Institute for Sport and Exercise Sciences, Journal Sports Sci. 18, Sep, 2000. 